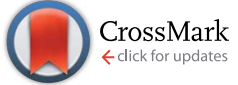

Cite this: RSC Adv., 2017, 7, 6422
Received 23rd November 2016 Accepted 29th December 2016

DOI: 10.1039/c6ra27221e

www.rsc.org/advances

\section{Pebax-based composite membranes with high gas transport properties enhanced by ionic liquids for $\mathrm{CO}_{2}$ separation $\uparrow$}

\author{
Mengdie Li, ${ }^{\text {ab }}$ Xiangping Zhang, ${ }^{\text {*a }}$ Shaojuan Zeng, ${ }^{a}$ Lu bai, ${ }^{a}$ Hongshuai Gao, ${ }^{a}$ \\ Jing Deng, ${ }^{\text {ab }}$ Qingyuan Yang ${ }^{c}$ and Suojiang Zhang ${ }^{* a}$
}

Membrane-based separation technology has been reported as one of the possible methods to efficiently and economically separate carbon dioxide $\left(\mathrm{CO}_{2}\right)$. To provide synergistic enhancements in the gas separation performance, organic polymer (Pebax 1657), zeolite imidazolate framework-8 (ZIF-8) nanoparticles, and ionic liquid (IL) have been integrated to develop three-component composite membranes. To achieve high separation performance of three-component membranes, the effects of IL anions and ZIF-8 content on gas permeability and selectivity were investigated first. The ILs were 1butyl-3-methyl imidazolium ([Bmim]) cation based on different anions of bis(trifluoromethylsulfonyl) imide $\left(\left[N \mathrm{Nf}_{2}\right]\right)$, dicyanamide ([DCA]), and tetrafluoroborate $\left(\left[\mathrm{BF}_{4}\right]\right)$. Gas transport properties of all the prepared membranes were investigated at $23{ }^{\circ} \mathrm{C}$ and 1 bar. The results showed that the anion of IL is a key factor to determine the $\mathrm{CO}_{2}$ permeability of the membranes, which is similar to the principle of $\mathrm{CO}_{2}$ solubility in pure ILs. In addition, ZIF-8 could increase both $\mathrm{CO}_{2}$ diffusivity and solubility coefficients of the Pebax/ZIF- 8 membranes, resulting in a two-fold increase in the $\mathrm{CO}_{2}$ permeability. For the Pebax/ $\mathrm{ZIF}-8(15 \%) /[\mathrm{Bmim}]\left[\mathrm{NTf}_{2}\right]$ membranes, it has been revealed that $[\mathrm{Bmim}]\left[\mathrm{NTf}_{2}\right]$ acts as a low molecular weight additive, leading to a more amorphous structure and a higher FFV (fractional free volume) of the membranes, which are beneficial for gas diffusion. The addition of IL can improve the compatibility between the inorganic particles and the polymer matrix; thus, the non-selective voids decrease, which leads to a higher $\mathrm{CO}_{2} / \mathrm{N}_{2}$ selectivity. The $\mathrm{CO}_{2}$ permeability of the Pebax/ZIF-8(15\%)/IL(80\%) membrane was 4.3 times that of the pure Pebax membrane without sacrificing the $\mathrm{CO}_{2} / \mathrm{N}_{2}$ selectivity. Therefore, the high gas transport properties of the Pebax/ZIF-8/IL membranes make them promising candidates for $\mathrm{CO}_{2}$-effective separation materials.

\section{Introduction}

Owing to global warming and increasing energy consumption, the efficient separation of $\mathrm{CO}_{2}$ has received significant interest. ${ }^{\mathbf{1 , 2}}$ During the last few decades, various methods have been developed for $\mathrm{CO}_{2}$ separation. Compared to the traditional methods, such as solvent absorption, pressure- and temperature-swing adsorption, and cryogenic distillation, the membrane method has become an emerging technology because of its advantages of environmentally friendliness, lower

${ }^{a}$ Beijing Key Laboratory of Ionic Liquids Clean Process, State Key Laboratory of Multiphase Complex Systems, Beijing Key Laboratory of Ionic Liquids Clean Process, Institute of Process Engineering, Chinese Academy of Sciences, Beijing 100190, China.E-mail:xpzhang@ipe.ac.cn; sjzhang@ipe.ac.cn

${ }^{b}$ School of Chemistry and Chemical Engineering, University of Chinese Academy of Sciences, Beijing 100049, China

${ }^{c}$ State Key Laboratory of Organic-Inorganic Composites, Beijing University of Chemical Technology, Beijing 100029, China

$\dagger$ Electronic supplementary information (ESI) available. See DOI: 10.1039/c6ra27221e energy consumption, and ability for scale up. ${ }^{3,4}$ Owing to the good mechanical stability and easy processability, polymeric membranes have attracted considerable attention and have been studied in the separation of biogas $\left(\mathrm{CO}_{2} / \mathrm{CH}_{4}\right)^{5,6}$ flue gas $\left(\mathrm{CO}_{2} / \mathrm{N}_{2}\right){ }^{7,8}$ syngas $\left(\mathrm{CO}_{2} / \mathrm{H}_{2}\right)^{,, 10}$ and other light gases. ${ }^{11}$ However, there is a trade-off between permeability and selectivity known as the "Robeson upper-bound" that limits the application of polymeric membranes for gas separation.

Hence, due to the difficulty in achieving a simultaneously high gas permeability and selectivity for a single polymer material, mixed-matrix membranes (MMMs), which are a blend of organic polymers and inorganic materials, offer an opportunity to overcome the trade-off limit. ${ }^{12-14}$ Inorganic materials, such as molecular sieves, carbon nanotubes, mesoporous materials, zeolites, and metal-organic frameworks, provide high gas flux and selectivity as well as good thermal and chemical stability in MMMs. ${ }^{13}$ However, challenges are encountered with the interfacial defects and poor adhesion between inorganic particles and polymer matrix. ${ }^{13}$ 
Ionic liquids (ILs) have been regarded as attractive absorbents of $\mathrm{CO}_{2}$ owing to their high $\mathrm{CO}_{2}$ absorption capacity, low volatility, and tunable characteristics. ${ }^{15}$ Some ILs, which have the cations, such as imidazolium, ammonium, phosphonium, pyridinium, and pyrrolidinium, and anions, such as bis(trifluoromethylsulfonyl)imide $\left(\left[\mathrm{NTf}_{2}\right]\right)$, tetrafluoroborate $\left(\left[\mathrm{BF}_{4}\right]\right)$, and dicyanamide ([DCA]), have been extensively used in $\mathrm{CO}_{2}$ absorption. ${ }^{16}$ Moreover, recent studies have shown that IL as an additive can enhance the interfacial adhesion between the polymer matrix and inorganic particles, as well as the $\mathrm{CO}_{2}$ adsorption. ${ }^{17,18}$ Mohshim's et al. ${ }^{19}$ found that incorporating [Emim] $\left.] \mathrm{NTf}_{2}\right]$ (1-ethyl-3-methyl imidazolium bis(trifluoromethylsulfonyl)imide) into PES (polyethersulfone)-SAPO-34 MMMs could reduce the agglomeration of the filler particles and produce defect-free mixed matrix membranes. Therefore, combining ILs with MMMs would offer an opportunity to improve the compatibility between the inorganic particles and polymer matrix as well as achieve good dispersion. Furthermore, IL-based membranes may be considered as an approach to avoid the lower diffusivity and flux caused by the high viscosities of ILs.

In this study, to achieve synergistic enhancements in the gas separation performance, organic polymer (Pebax 1657), zeolite imidazolate framework-8 (ZIF-8) nanoparticles, and ionic liquid (IL) were integrated to develop three-component membranes. Poly(ether- $b$-amide-6) (Pebax 1657) was selected as the polymer matrix because of its easy film formation, economical feasibility, and relatively high $\mathrm{CO}_{2}$ separation performance. The soft PEO segments in Pebax can act as a permeable phase because of its high chain mobility and high affinity of the EO unit for the $\mathrm{CO}_{2}$ molecule. In addition, the hard PA segments in Pebax can impart mechanical stability to the polymer. ${ }^{\mathbf{2 0} 21}$ Zeolite imidazolate framework-8 (ZIF-8) was chosen as the inorganic filler because it has certain selectivity towards $\mathrm{CO}_{2}$ and is widely used in $\mathrm{CO}_{2} / \mathrm{CH}_{4}, \mathrm{CO}_{2} / \mathrm{N}_{2}$ separation. ${ }^{22,23}$ [Bmim] cation-based ILs were selected because the imidazolium group tends to have excellent $\mathrm{CO}_{2}$ solubility. ${ }^{24}$

For better preparation of the three-component composite membranes, Pebax/IL membranes composed of three types of anion, $\left[\mathrm{NTf}_{2}\right],[\mathrm{DCA}]$, and $\left[\mathrm{BF}_{4}\right]$, and Pebax/ZIF-8 composite membranes with a ZIF-8 content varying from $0-20 \mathrm{wt} \%$ have been firstly studied. The chemical structures of Pebax 1657 and ILs used in this study are shown in Fig. 1. The membranes prepared in this study were characterized by FTIR (Fourier transform infrared spectroscopy), XRD (X-ray diffraction), and
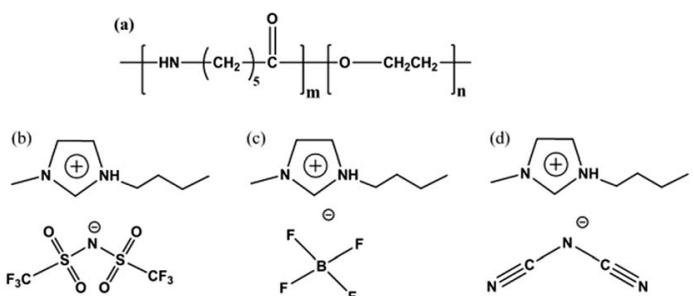

Fig. 1 Chemical structures of (a) Pebax 1657, (b) [Bmim] $\left[\mathrm{NTf}_{2}\right]$, (c) $[\mathrm{Bmim}]\left[\mathrm{BF}_{4}\right]$, and (d) $[\mathrm{Bmim}][\mathrm{DCA}]$.
SEM (scanning electron microscopy). The thermal properties were measured by DSC (differential scanning calorimetry) and TGA (thermogravimetric analysis). The gas permeability $(P)$, selectivity $(\alpha)$, diffusivity coefficients $(D)$, and solubility coefficients $(S)$ of the membranes were systematically studied at $23{ }^{\circ} \mathrm{C}$ and 1 bar.

\section{Experimental}

\subsection{Materials}

Pebax 1657 (containing 60\% PEO and 40\% PA) was provided by Shanghai Connell Bros. Company. ZIF-8 was purchased from Sigma-Aldrich. [Bmim $]\left[\mathrm{NTf}_{2}\right],[\mathrm{Bmim}][\mathrm{DCA}]$, and $[\mathrm{Bmim}]\left[\mathrm{BF}_{4}\right]$ were supplied by the Linzhou Keneng Materials Technology Co., Ltd. Ethanol was purchased from Beijing Chemical Works, and deionized water was used throughout the study. The gases $\left(\mathrm{CO}_{2}\right.$ $99.99 \%, \mathrm{CH}_{4} 99.99 \%$, and $\mathrm{N}_{2}$ 99.99\%) used in the permeation experiment were supplied by Beijing Beiwen Gas Factory.

\subsection{Preparation of membranes}

2.2.1 Pebax/IL and Pebax/ZIF-8 composite membranes. Pebax solution ( $8 \mathrm{wt} \%$ ) was prepared by dissolving the Pebax pellets in a mixture of ethanol/water (70/30 depending on weight) at $80{ }^{\circ} \mathrm{C}$ under reflux and vigorous stirring for at least $8 \mathrm{~h}$. After cooling the Pebax solution down to ambient temperature, a certain amount of IL or ZIF-8 particles were slowly added to the Pebax solution. In this study, the content was based on the weight of the polymer Pebax 1657. To avoid the agglomeration of ZIF-8, the solution was ultrasonicated for at least $3 \mathrm{~h}$ and stirred for $10 \mathrm{~min}$ after $30 \mathrm{~min}$ ultrasonication. After stirring overnight under ambient conditions, the homogeneous solution was cast onto a square glass plate and dried under ambient conditions for $24 \mathrm{~h}$. Finally, all the membranes were dried in a vacuum oven at $50{ }^{\circ} \mathrm{C}$ for two days to remove the residual solvent.

2.2.2 Pebax/ZIF-8/IL three-component composite membranes. The three-composite membranes were prepared following a similar abovementioned procedure. In a typical experiment, a certain amount of IL was first added to the Pebax solution and completely dissolved during $2 \mathrm{~h}$ stirring. Then, ZIF-8 particles were added to the solution and stirred for another $24 \mathrm{~h}$. Finally, the homogeneous solution was cast onto a square glass plate and dried in a vacuum oven to remove the solvent.

\subsection{Characterization of the membranes}

The FTIR spectra were obtained by a Thermo Nicolet 380 spectrometer in the range of 750-4000 $\mathrm{cm}^{-1}$ under ambient conditions. The thermal properties of the membranes were investigated over the temperature range from $-100{ }^{\circ} \mathrm{C}$ to $250{ }^{\circ} \mathrm{C}$ at a heating rate of $10{ }^{\circ} \mathrm{C} \min ^{-1}$ under $\mathrm{N}_{2}$ atmosphere by Mettler-Toledo DSC1. DTG-60H was used to determine the weight changes as a function of temperature over time in a $\mathrm{N}_{2}$ controlled atmosphere at $10{ }^{\circ} \mathrm{C} \min ^{-1}$ from $50{ }^{\circ} \mathrm{C}$ to $550{ }^{\circ} \mathrm{C}$. $\mathrm{XRD}$ patterns of the prepared membranes were obtained using a Smartlab $(9 \mathrm{~kW})$ from 5 to $60^{\circ} 2 \theta$ values at a rate of $10^{\circ} \mathrm{min}^{-1}$. 
Scanning electron microscopy was performed using a SU8020 to analyze the morphological structure of the composite membranes. Before scanning, the samples required to be fractured in liquid nitrogen, and then coated with gold.

\subsection{Gas permeation experiments}

Gas permeability tester (VAC-V2, Labthink) was used to examine the pure gas permeation of these prepared membranes with the constant volume/variable pressure method. All the test gases were proceeded in the order of $\mathrm{N}_{2}, \mathrm{CH}_{4}$, and $\mathrm{CO}_{2}$ at $23{ }^{\circ} \mathrm{C}$ and 1 bar. Before each test, the permeate side of the membrane was evacuated. The gas permeability $(P)$, diffusion coefficient $(D)$, solution coefficient $(S)$, and ideal selectivity $\left(\alpha_{\mathrm{A} / \mathrm{B}}\right)$ of the membranes were calculated using the following equations:

$$
P=\frac{\Delta p}{\Delta t} \times \frac{V}{A} \times \frac{T_{0}}{P_{0} T} \times \frac{d}{\left(p_{1}-p_{2}\right)}
$$

where $P$ represents the gas permeability [barrer, 1 barrer $=$ $10^{-10} \mathrm{~cm}^{3}$ (STP) per $\mathrm{cm}$ per $\left.\left(\mathrm{cm}^{2} \mathrm{~s} \mathrm{~cm} \mathrm{Hg}\right)\right]$ and $A$ stands for the area of the membrane $\left(\mathrm{cm}^{2}\right)$. The active membrane area for the gas permeation measurements in this experiment was $4.9 \mathrm{~cm}^{2}$. $V$ means the downstream volume $\left(\mathrm{cm}^{3}\right), T$ is the operating temperature $(\mathrm{K}), d$ represents the membrane thickness $(\mathrm{cm})$, and the thickness of the prepared membranes for the permeability measurement is listed in Table $\mathrm{S} 1 . \dagger\left(p_{1}-p_{2}\right)$ means the transmembrane pressure difference ( $\mathrm{cm} \mathrm{Hg}$ ), $\Delta p / \Delta t$, is the arithmetic average of the gas pressure changes in the low pressure chamber in unit time when the gas stably permeates through the membrane, $T_{0}$ and $P_{0}$ means the temperature $(273.15 \mathrm{~K})$ and pressure $\left(1.0133 \times 10^{5} \mathrm{~Pa}\right)$ under standard conditions.

$D$ is the diffusion coefficient $\left(\mathrm{cm}^{2} \mathrm{~s}^{-1}\right)$, which can be determined by the time-lag $(\theta)$ method.

$$
D=\frac{d^{2}}{\sigma \theta}
$$

Based on the solution-diffusion mechanism, the solubility coefficients $(S)$ can be obtained from eqn (3):

$$
S=\frac{P}{D}
$$

The ideal selectivity $\alpha_{\mathrm{A} / \mathrm{B}}$ can be calculated from eqn (4):

$$
\alpha_{\mathrm{A} / \mathrm{B}}=\frac{P_{\mathrm{A}}}{P_{\mathrm{B}}}
$$

\section{Results and discussion}

\subsection{Characterization of the membranes}

3.1.1 Fourier transform infrared (FTIR) spectroscopy. The interaction between Pebax 1657, ZIF-8, and IL can be investigated from the FTIR spectra, as shown in Fig. 2. For the pure Pebax membranes, the characteristic peaks at around 1102, 1733 , and $2867 \mathrm{~cm}^{-1}$ are the stretching vibrations of $\mathrm{C}-\mathrm{O}, \mathrm{C}=\mathrm{O}$, and $-\mathrm{CH}_{3}$, respectively. The peaks at 1638 and $3300 \mathrm{~cm}^{-1}$ were

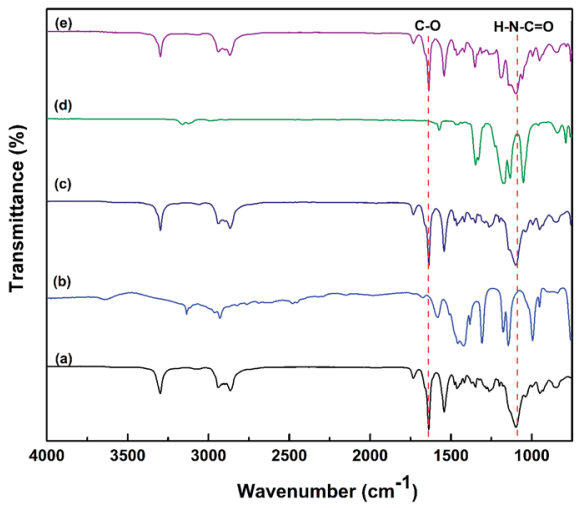

Fig. 2 FTIR spectra of (a) Pebax, (b) ZIF-8, (c) Pebax-ZIF-8(15\%), (d) [Bmim][NTf $\left.{ }_{2}\right]$, and (e) Pebax-ZIF-8(15\%)-IL(20\%) composite membranes.

assigned to the $\mathrm{H}-\mathrm{N}-\mathrm{C}=\mathrm{O}$ and $\mathrm{N}-\mathrm{H}$ group, respectively. ${ }^{25}$ The bands for ZIF-8 at $1580 \mathrm{~cm}^{-1}$ and $1145,990 \mathrm{~cm}^{-1}$ correspond to the $\mathrm{C}=\mathrm{N}$ and $\mathrm{C}-\mathrm{N}$ stretching, respectively. ${ }^{26}$ Several FTIR peaks corresponding to $[\mathrm{Bmim}]\left[\mathrm{NTf}_{2}\right], 1055 \mathrm{~cm}^{-1}$ ( $\mathrm{S}=\mathrm{O}$ bending), $1431 \mathrm{~cm}^{-1}$ ( $\mathrm{C}=\mathrm{C}$ stretching), $1575 \mathrm{~cm}^{-1}(\mathrm{C}=\mathrm{N}$ stretching), and 1250-1150 $\mathrm{cm}^{-1}$ (C-F stretching), 3000-2900 $\mathrm{cm}^{-1}$ (C-H stretching), and $3200-3000 \mathrm{~cm}^{-1}$ (ring $\mathrm{C}-\mathrm{H}$ stretching) were observed. ${ }^{27}$ In addition, the spectra of the pure IL, ZIF-8, and Pebax showed no new peaks for all the composite membranes, implying the physical blending feature of ZIF-8 and [Bmim] $\left[\mathrm{NTf}_{2}\right]$ within the Pebax bulk.

3.1.2 X-ray diffraction (XRD). XRD patterns of Pebax, ZIF-8, and Pebax composite membranes were obtained to further investigate their nanostructures (Fig. 3). The pure Pebax is a semicrystalline copolymer containing a crystalline phase (PA) and an amorphous phase (PEO), with diffraction peaks at 13.70, $16.52,23.68$, and $25.10^{\circ}(2 \theta)$, and the peaks at $23.70^{\circ}$ and $25.16^{\circ}$ result from the crystalline PA and PEO phase, respectively. ${ }^{25,28}$ For pure ZIF-8, there are diffraction peaks at $2 \theta=7.26,10.32$, $12.66,14.64,16.38$, and $17.96^{\circ}$ for the $\{110\},\{200\},\{211\},\{220\}$, $\{310\}$, and $\{222\}$ planes, respectively. ${ }^{29}$ When the ZIF-8 content reached $15 \mathrm{wt} \%$, there were characteristic peaks of ZIF-8 arising

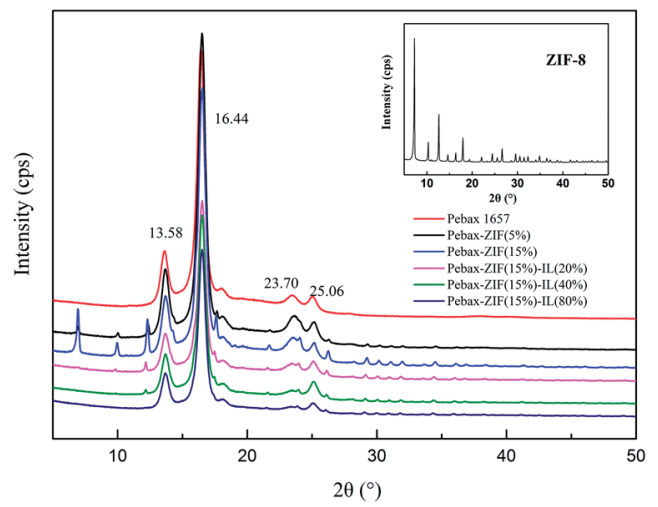

Fig. 3 XRD patterns of Pebax, ZIF-8, and Pebax composite membranes. 
in the spectra of Pebax/ZIF-8 composite membranes. The addition of IL and ZIF-8 slightly decreased the $d$-spacing of the diffraction peak at $23.70^{\circ}$, indicating that the inter-chain hydrogen bonding between PA segments in Pebax is disturbed and amorphous region increases within the membranes. ${ }^{30}$

3.1.3 Thermal properties of the prepared membranes. The thermal properties of IL, ZIF-8, Pebax, and Pebax composite membranes were investigated by differential scanning calorimetry (DSC) and thermogravimetric analysis (TGA). The DSC curves of Pebax and Pebax composite membranes are shown in Fig. $\mathrm{S} 1 \dagger$ and the glass transition temperatures $\left(T_{\mathrm{g}}\right)$ are listed in Table 1. The results show that $T_{\mathrm{g}}$ of Pebax/ZIF-8 membranes increases with the increasing ZIF-8 content due to polymer chain rigidification caused by the interactions between ZIF-8 and Pebax polymer. ${ }^{31}$ However, $T_{\mathrm{g}}$ of the Pebax/ZIF-8/IL membranes decreases with the increasing IL content, implying a higher chain mobility of the polymer matrix. ${ }^{32}$ For the pure Pebax membrane, two characteristic melting peaks were observed at around 19 and $206^{\circ} \mathrm{C}$, which were assigned to the melting point of PEO crystals and PA crystallites. With the addition of ZIF-8 and IL, the melting peaks of PA segment for all Pebax-based membranes were shifted to a lower temperature, resulting from the reduction in the crystallinity and increase in the chain mobility. In addition, the melting peaks of PEO become weaker with the addition of IL and even disappear after $30 \mathrm{wt} \%$ IL content. This is due to the decrease in the PEO crystallinity and the miscibility of PEO and IL. ${ }^{33}$

Furthermore, the crystallinity of the prepared membranes was calculated using the DSC thermograms according to eqn (5):

$$
X_{\text {crystallinity }}=\frac{\Delta H_{\mathrm{m}}}{\Delta H_{\mathrm{m}}^{0}} \times 100 \%
$$

where $\Delta H_{\mathrm{m}}$ is the heat of melting of the crystals and can be calculated by integrating the area of the melting peaks, $\Delta H_{\mathrm{m}}^{0}$ represents the heat of melting as if the polymer is $100 \%$ crystalline. $\Delta H_{\mathrm{m}}^{0}$ of PEO $\left(166.4 \mathrm{~J} \mathrm{~g}^{-1}\right)$ and PA $\left(230.0 \mathrm{~J} \mathrm{~g}^{-1}\right)$ were obtained from the literature. ${ }^{34}$ The total crystallinity $\left(X_{\text {crystallinity }}\right)$ of the prepared membranes was calculated by considering $40 \%$ PA crystallinity and $60 \%$ PEO crystallinity. ${ }^{32}$ The calculation results are also listed in Table 1. Both ZIF-8 and IL decrease the total crystallinity of the prepared membranes, leading to a greater chain mobility and higher fractional free volume (FFV) of the membranes, which are beneficial for gas diffusion. ${ }^{35}$

In addition, the thermal stabilities of the membranes were also studied by thermogravimetric analysis (TGA). The TGA curves of ZIF-8, [Bmim] [NTf $\left.{ }_{2}\right]$, and prepared membranes are shown in Fig. S2. $\dagger$ The decomposition temperatures $\left(T_{\mathrm{d}}\right)$ at $5 \%$ weight loss are listed in Table 1 . The results show that $T_{\mathrm{d}}$ of the Pebax 1657 membrane, IL, and ZIF-8 is $363.86,380.70$, and $495.94{ }^{\circ} \mathrm{C}$, respectively. The addition of ZIF-8 decreases the $T_{\mathrm{d}}$ of the Pebax/ZIF-8 membranes compared to that of the pure Pebax membrane. However, the addition of IL does not significantly change the $T_{\mathrm{d}}$ of the Pebax/ZIF-8/IL membranes compared to that of the Pebax/ZIF-8 membrane at 15 wt\% ZIF-8. The Pebax/ ZIF-8/IL membranes display two-step decomposition; the first step is around $360{ }^{\circ} \mathrm{C}$ based on Pebax and the second one is around $380^{\circ} \mathrm{C}$ based on the IL. Overall, the $T_{\mathrm{d}}$ of Pebax, Pebax/ ZIF-8, and Pebax/ZIF-8/IL membranes was all above $330{ }^{\circ} \mathrm{C}$, implying that all the prepared membranes have excellent thermal stability.

3.1.4 Scanning electron microscopy (SEM). SEM images of the surface and cross-sectional morphology of the prepared membranes are presented in Fig. 4 and 5, respectively. Fig. 4(a) and (b) show that pure Pebax membrane has a homogeneous, smooth surface, and the surface of the Pebax/ZIF-8 membranes becomes rougher with the addition of ZIF-8. Moreover, the ZIF-8 particles can be obviously observed in the cross-section of the Pebax/ZIF-8 membrane at $15 \mathrm{wt} \%$ ZIF-8 content, and a few microsized ZIF-8 agglomerates can be observed in Fig. 5(b). Compared to the Pebax/ZIF-8(15\%) membrane, the surface of the Pebax/ZIF-8/IL membranes is smoother and the structure of the membranes becomes more amorphous with the increasing IL content. This may be attributed to the reduction in the

Table 1 Physical properties of the ZIF-8, IL, Pebax, and Pebax composite membranes

\begin{tabular}{|c|c|c|c|c|c|c|c|}
\hline & $T_{\mathrm{d}}^{a}\left({ }^{\circ} \mathrm{C}\right)$ & $T_{\mathrm{g}}{ }^{b}\left({ }^{\circ} \mathrm{C}\right)$ & \multicolumn{2}{|c|}{$\Delta H_{\mathrm{m}}\left(\mathrm{J} \mathrm{g}^{-1}\right)$} & \multicolumn{3}{|c|}{$X_{\text {crystallinity }}{ }^{c}(\%)$} \\
\hline Pebax-ZIF(5\%) & 334.01 & -49.45 & 23.49 & 24.76 & 14.12 & 10.77 & 12.78 \\
\hline Pebax-ZIF(15\%) & 335.76 & -47.31 & 19.78 & 21.25 & 11.89 & 9.24 & 10.83 \\
\hline Pebax-ZIF(15\%)-IL(5\%) & 336.37 & -48.86 & 17.62 & 21.02 & 10.59 & 9.14 & 10.01 \\
\hline Pebax-ZIF(15\%)-IL(30\%) & 330.52 & -53.43 & - & 16.42 & - & 7.14 & 2.86 \\
\hline Pebax-ZIF(15\%)-IL(40\%) & 331.37 & -54.05 & - & 15.52 & - & 6.75 & 2.70 \\
\hline Pebax-ZIF(15\%)-IL(60\%) & 333.56 & -55.71 & - & 13.29 & - & 5.78 & 2.31 \\
\hline Pebax-ZIF(15\%)-IL(80\%) & 336.22 & -57.78 & - & 10.14 & - & 4.41 & 1.76 \\
\hline ZIF-8 & 495.94 & - & - & - & - & - & - \\
\hline$[\mathrm{Bmim}]\left[\mathrm{NTf}_{2}\right]$ & 380.70 & -96.37 & - & - & - & - & - \\
\hline
\end{tabular}

${ }^{a}$ Decomposition temperature of the prepared membranes, ZIF-8, and [Bmim $]\left[\mathrm{NTf}_{2}\right] .{ }^{b}$ Glass transition temperature of the prepared membranes and $[\mathrm{Bmim}]\left[\mathrm{NTf}_{2}\right]{ }^{c}$ Total crystallinity of the prepared membranes. 

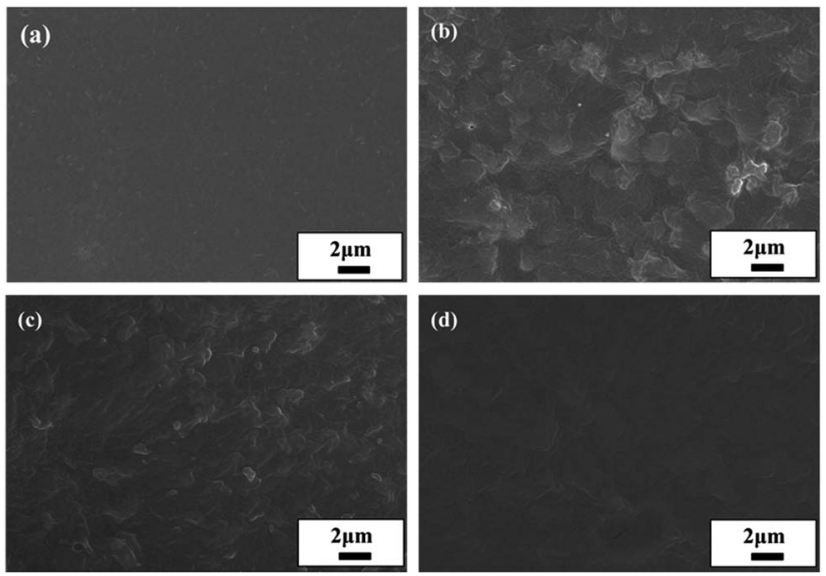

Fig. 4 SEM images for the surface morphology of the prepared membranes. (a) Pure Pebax membrane, (b) Pebax-ZIF(15\%) membrane, (c) Pebax-ZIF(15\%)-IL(20\%) membrane, and (d) Pebax-ZIF(15\%)IL(80\%) membrane.
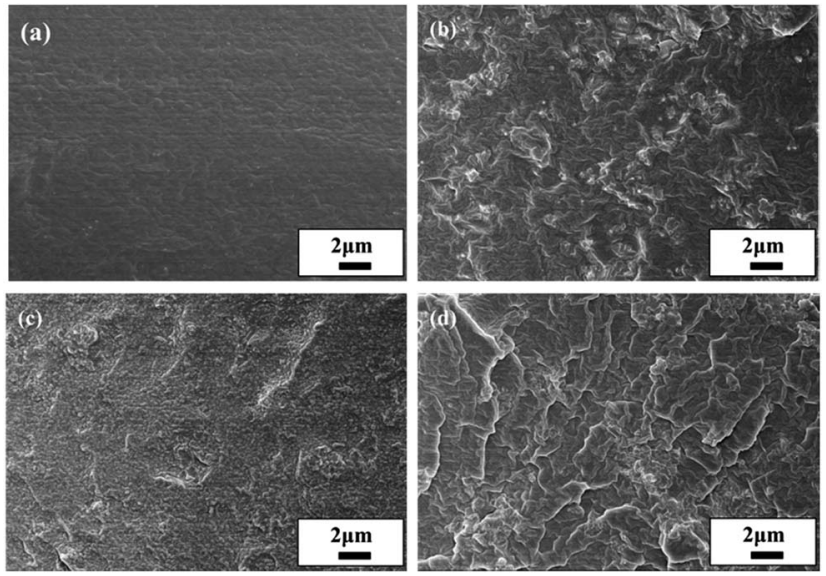

Fig. 5 SEM images of the cross-section morphology of the prepared membranes. (a) Pure Pebax membrane, (b) Pebax-ZIF(15\%) membrane, (c) Pebax-ZIF(15\%)-IL(20\%) membrane, and (d) Pebax-ZIF(15\%)IL(80\%) membrane.

crystallinity and is in accordance with the plasticization effects of the low-molecular weight additives reported in some studies. $^{32,34}$ Fig. 5(c) and (d) show that IL decreases the interfacial voids between Pebax and ZIF-8. At $80 \mathrm{wt} \%$ IL content, and the amorphous morphology is quite clear, which will have a great impact on the diffusivity coefficients of the prepared membranes.

\subsection{Gas separation performance of the Pebax/IL composite membranes}

3.2.1 Effect of the IL anion on the gas permeability of the Pebax/IL composite membranes. The effect of the IL anion on the gas permeability of the Pebax/IL composite membranes was studied and is shown in Fig. 6 . The permeability of $\mathrm{N}_{2}, \mathrm{CH}_{4}$, and $\mathrm{CO}_{2}$ for all the Pebax/IL membranes obviously increased compared to that for the pure Pebax membrane. For example,
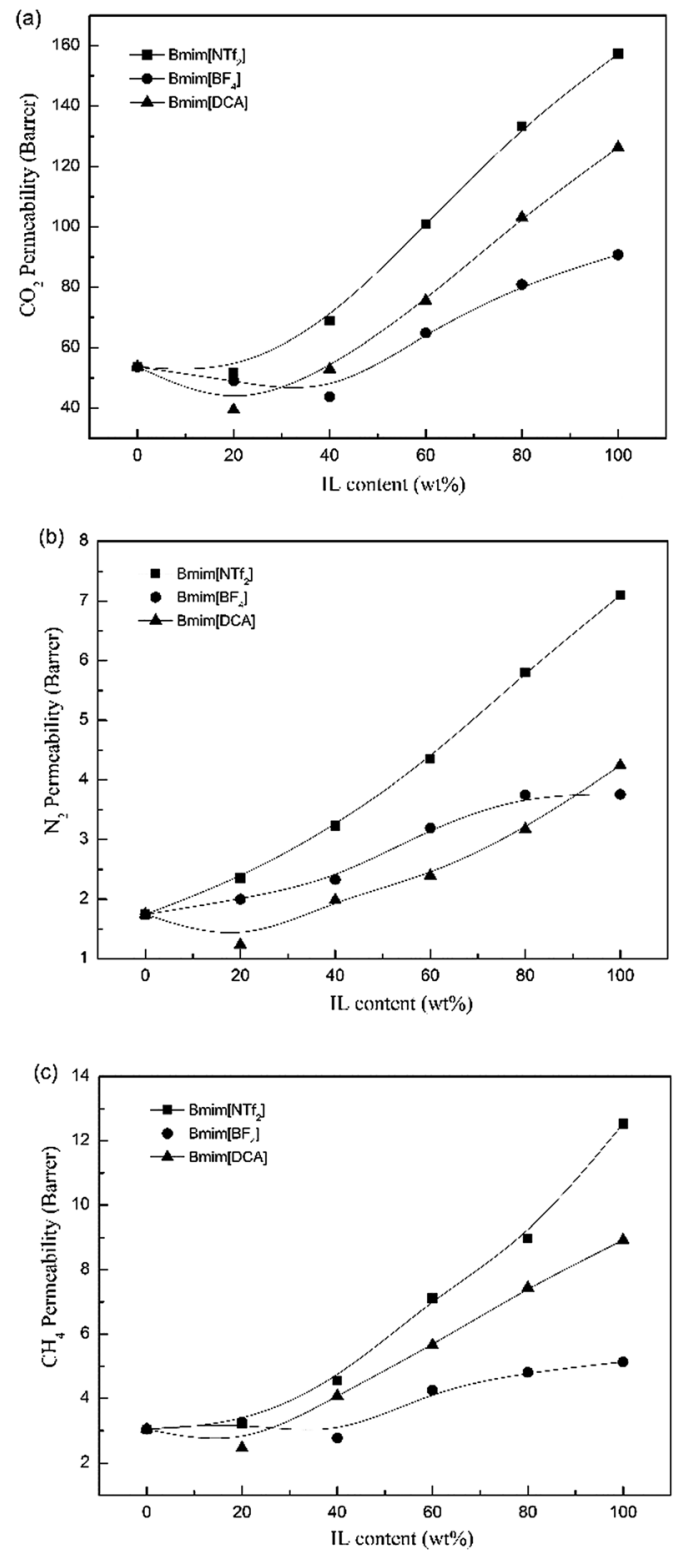

Fig. 6 Gas permeabilities of (a) $\mathrm{CO}_{2}$, (b) $\mathrm{N}_{2}$, and (c) $\mathrm{CH}_{4}$ for the Pebax/ $\mathrm{IL}$ membranes as a function of IL content.

Pebax-[Bmim] $]\left[\mathrm{BF}_{4}\right](100 \%), \quad$ Pebax-[Bmim $][\mathrm{DCA}](100 \%), \quad$ and Pebax-[Bmim][NTf $](100 \%)$ membranes exhibit higher $\mathrm{CO}_{2}$ permeability of 90.8, 126.4, and 157.3 barrer, respectively, vs. 53.70 barrer for the pure Pebax membrane. Moreover, $\mathrm{CO}_{2}$ permeability of the Pebax/IL membranes was in the following order: Pebax/[Bmim $]\left[\mathrm{NTf}_{2}\right]>\operatorname{Pebax} /[\mathrm{Bmim}][\mathrm{DCA}]>$ Pebax/ $[\mathrm{Bmim}]\left[\mathrm{BF}_{4}\right]$. It was demonstrated by some researchers that the anion plays a primary role in the $\mathrm{CO}_{2}$ solubility for the conventional ILs. The solubility of $\mathrm{CO}_{2}$ in the $[\mathrm{Bmim}]^{+}$-based ILs increases in the following order: $\left[\mathrm{BF}_{4}\right]^{-}<[\mathrm{DCA}]^{-}<\left[\mathrm{NTf}_{2}\right]^{-}$at $25{ }^{\circ} \mathrm{C}$, according to the Henry's law constants reported by Lei. ${ }^{15}$ It reveals that the anion is still a key factor to determine the $\mathrm{CO}_{2}$ permeability of the Pebax/IL membranes, which are familiar with the principle of $\mathrm{CO}_{2}$ in pure ILs. The gas permeability of $\mathrm{N}_{2}$ and $\mathrm{CH}_{4}$ follow the order Pebax/[Bmim $]\left[\mathrm{NTf}_{2}\right]>\operatorname{Pebax} /[\mathrm{Bmim}]$ 

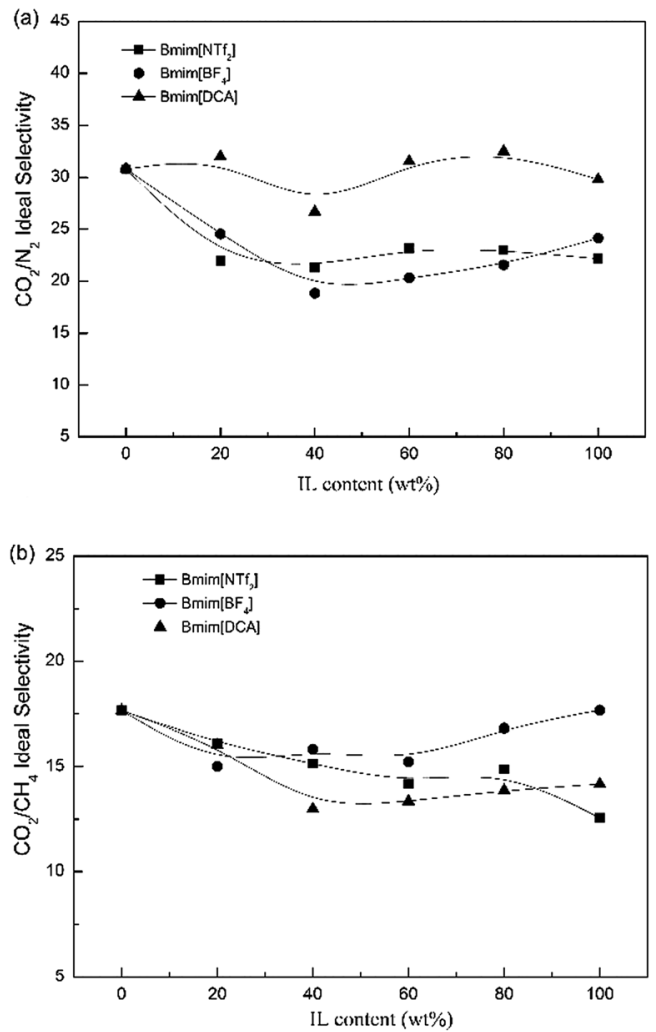

Fig. 7 Ideal selectivities of (a) $\mathrm{CO}_{2} / \mathrm{N}_{2}$ and (b) $\mathrm{CO}_{2} / \mathrm{CH}_{4}$ for the Pebax/ IL membranes as a function of IL content.

$\left[\mathrm{BF}_{4}\right]>\operatorname{Pebax} /[\mathrm{Bmim}][\mathrm{DCA}]$ and Pebax $/[$ Bmim $]\left[\mathrm{NTf}_{2}\right]>$ Pebax/ $[\mathrm{Bmim}][\mathrm{DCA}]>\operatorname{Pebax} /[\mathrm{Bmim}]\left[\mathrm{BF}_{4}\right]$, respectively.

3.2.2 Effect of the IL anion on the gas selectivity of the Pebax/IL composite membranes. The $\mathrm{CO}_{2} / \mathrm{N}_{2}$ and $\mathrm{CO}_{2} / \mathrm{CH}_{4}$ selectivities of the Pebax/IL composite membranes are presented in Fig. 7. Compared to that of the pure Pebax membranes, the $\mathrm{CO}_{2} / \mathrm{N}_{2}$ selectivity of the Pebax/[Bmim $]\left[\mathrm{NTf}_{2}\right]$ and Pebax/[Bmim $]\left[\mathrm{BF}_{4}\right]$ composite membranes decreased, whereas that of the Pebax/[Bmim $][\mathrm{DCA}]$ membranes was nearly constant with the increasing IL content. For the Pebax/[Bmim] $\left[\mathrm{NTf}_{2}\right]$ and Pebax/[Bmim $][\mathrm{DCA}]$ membranes, there is a slight decrease in the $\mathrm{CO}_{2} / \mathrm{CH}_{4}$ selectivity. Furthermore, the selectivity of $\mathrm{CO}_{2} / \mathrm{N}_{2}$ and $\mathrm{CO}_{2} / \mathrm{CH}_{4}$ for the Pebax/IL composite membranes was in the following order: Pebax/[Bmim $][$ DCA $]>$ Pebax $/[\mathrm{Bmim}]$ $\left[\mathrm{NTf}_{2}\right]>\operatorname{Pebax} /[\mathrm{Bmim}]\left[\mathrm{BF}_{4}\right]$ and Pebax/[Bmim $]\left[\mathrm{BF}_{4}\right]>$ Pebax/ $[$ Bmim $]\left[\mathrm{NTf}_{2}\right]>$ Pebax/[Bmim $][$ DCA $]$, respectively. This suggests that the selectivity of the Pebax/IL membranes depends on the affinity of the IL for the polymer and the inherent gas selectivity capacity of the ILs. Overall, [Bmim $]\left[\mathrm{NTf}_{2}\right]$ shows an optimal $\mathrm{CO}_{2}$ permeability and has been developed to prepare the threecomponent membranes in the following experiments. The mechanism of the effect of IL addition on gas separation performance has been discussed in Section 3.4.

\subsection{Gas separation performance of the Pebax/ZIF-8 composite membranes}

3.3.1 Effect of ZIF-8 addition on the gas diffusivity and solubility coefficients. Fig. 8 shows that the order of the
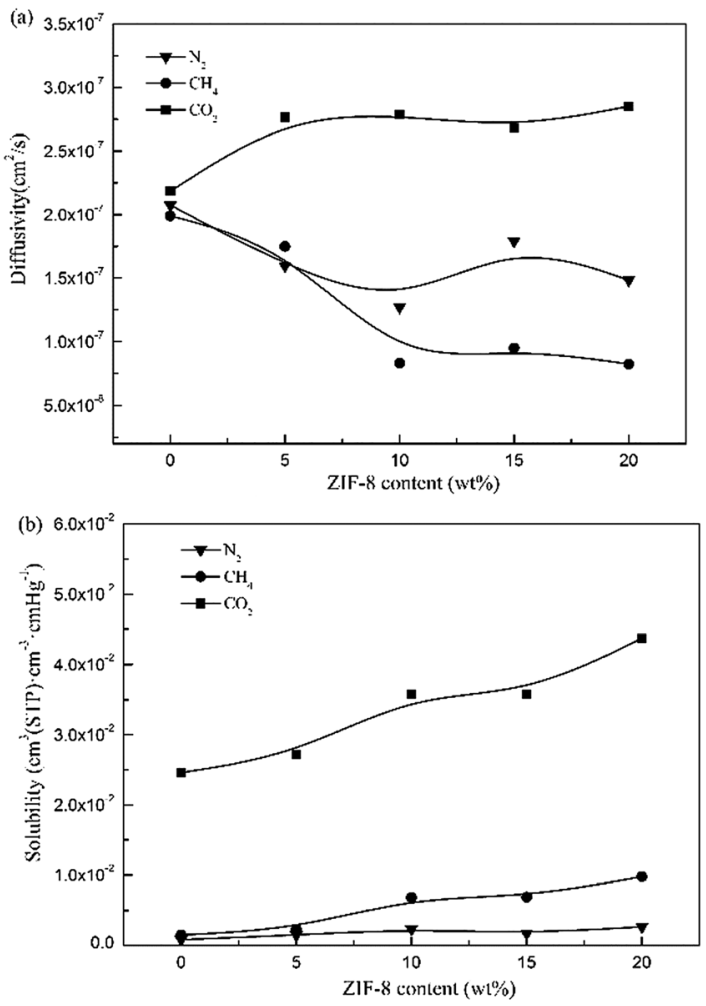

Fig. 8 (a) Diffusivity coefficients and (b) solubility coefficients of $\mathrm{N}_{2}$, $\mathrm{CH}_{4}$, and $\mathrm{CO}_{2}$ for pure Pebax membranes and Pebax/ZIF-8 composite membranes as a function of ZIF-8 content.

diffusivity coefficients for the pure Pebax membrane is $\mathrm{CH}_{4}<$ $\mathrm{N}_{2}<\mathrm{CO}_{2}$. For pure polymeric membranes, the diffusivity coefficients mainly depend on the kinetic diameter, based on the solution-diffusion model. ${ }^{25}$ Therefore, the experimental results are consistent with the theoretical results because the order of kinetic diameter is $\mathrm{CH}_{4}(0.38 \mathrm{~nm})>\mathrm{N}_{2}(0.36 \mathrm{~nm})>\mathrm{CO}_{2}$ $(0.33 \mathrm{~nm})$. The diffusivity coefficients of $\mathrm{CO}_{2}$ for the Pebax/ZIF8 membranes increase with the ZIF- 8 addition, owing to the reduction of polymer crystallinity, as shown in Fig. 4 and Table $1 .^{30,36}$ Moreover, the agglomeration of ZIF-8 may produce narrow gaps or voids to facilitate gas diffusion, as observed in the SEM images. However, the diffusivity coefficients of $\mathrm{N}_{2}$ and $\mathrm{CH}_{4}$ showed an opposite trend. The cavity diameter of ZIF-8 was $0.34 \mathrm{~nm}$, whereas the kinetic diameter of $\mathrm{N}_{2}$ and $\mathrm{CH}_{4}$ was $0.36 \mathrm{~nm}$ and $0.38 \mathrm{~nm}$, respectively. Therefore, ZIF-8 favors the diffusion of $\mathrm{CO}_{2}$, whereas $\mathrm{N}_{2}$ and $\mathrm{CH}_{4}$ could not easily diffuse. Therefore, the diffusivity coefficients of $\mathrm{N}_{2}$ and $\mathrm{CH}_{4}$ decrease.

Fig. 8(b) shows that the solubility coefficients of the Pebax/ ZIF-8 composite membranes for all the gases increase with the addition of ZIF-8 due to the affinity between $\mathrm{N}_{2}, \mathrm{CH}_{4}$, and ZIF-8. ${ }^{37}$ In addition, $\mathrm{CO}_{2}$ has the highest solubility coefficients compared to those of $\mathrm{N}_{2}$ and $\mathrm{CH}_{4}$. The high solubility coefficients of $\mathrm{CO}_{2}$ are due to the high $\mathrm{CO}_{2}$ condensability and the quadrupole-dipole interaction between the $\mathrm{CO}_{2}$ molecules and EO units. ${ }^{35,38}$ In general, the gas permeability is determined by both diffusivity coefficients and solubility coefficients according to the solution-diffusion model $(P=S \times D)$. 


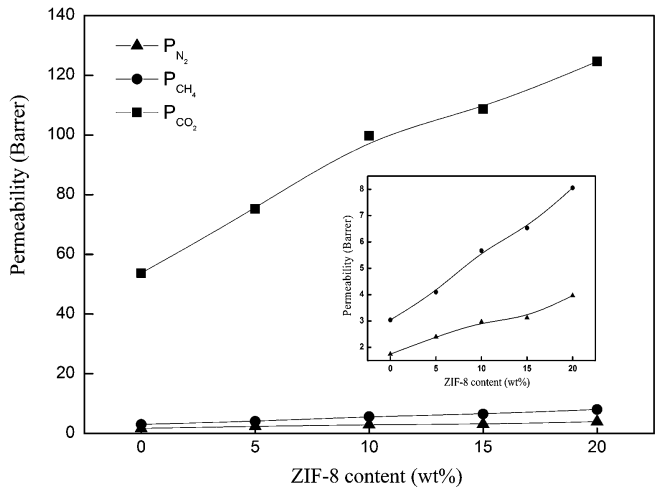

Fig. 9 Gas permeability of $\mathrm{N}_{2}, \mathrm{CH}_{4}$, and $\mathrm{CO}_{2}$ for the pure Pebax membrane and Pebax/ZIF-8 membranes as a function of ZIF-8 content.

3.3.2 Effect of ZIF-8 addition on the gas permeability and selectivity. Fig. 9 shows that the $\mathrm{CO}_{2}$ permeability of the Pebax/ ZIF-8 membranes dramatically increases with the addition of ZIF-8, from 53.7 barrer to 124.6 barrer with the addition of ZIF-8 content from $0-20 \mathrm{wt} \%$, which is approximately $132 \%$ higher than that of the pure Pebax membrane. The permeabilities of $\mathrm{N}_{2}$ and $\mathrm{CH}_{4}$ also increased by $128 \%$ and $165 \%$ compared to that of the pure Pebax membrane. The increase in the $\mathrm{CO}_{2}$ permeability is mainly due to the rapid gas diffusivity and high solubility with the addition of ZIF-8. The permeabilities of $\mathrm{N}_{2}$ and $\mathrm{CH}_{4}$ still increased, whereas the diffusivity coefficients decreased because of the significantly enhanced solubility coefficients. This suggests that gas transport in the Pebax/ZIF-8 membranes is more solubility-controlled, which is general for the rubbery polymer membranes. ${ }^{39}$

The selectivities of the pure Pebax membrane and Pebax/ZIF8 membranes for $\mathrm{CO}_{2} / \mathrm{N}_{2}$ and $\mathrm{CO}_{2} / \mathrm{CH}_{4}$ are shown in Fig. 10. The addition of ZIF-8 slightly increases the $\mathrm{CO}_{2} / \mathrm{N}_{2}$ selectivity for the Pebax/ZIF-8 membranes compared to that of the pure Pebax membrane, and the highest $\mathrm{CO}_{2} / \mathrm{N}_{2}$ selectivity was 34.79 at 15 wt\% ZIF-8. In addition, there was no significant change in the $\mathrm{CO}_{2} / \mathrm{CH}_{4}$ selectivity of the Pebax/ZIF-8 membranes. Therefore,

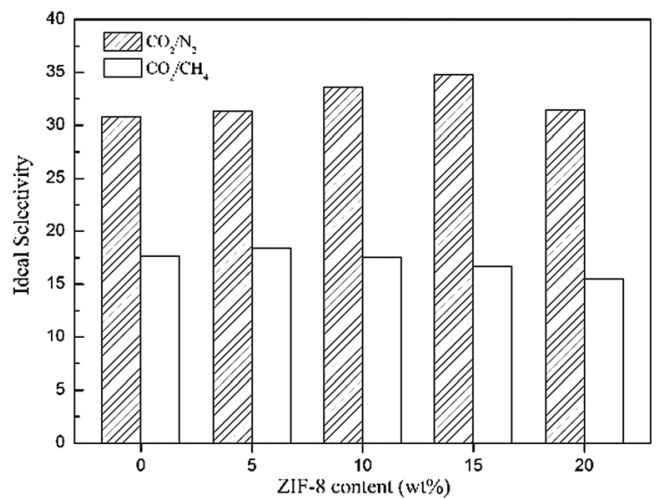

Fig. 10 Ideal selectivity of the pure Pebax membrane and Pebax/ZIF-8 membranes for $\mathrm{CO}_{2} / \mathrm{N}_{2}$ and $\mathrm{CO}_{2} / \mathrm{CH}_{4}$ as a function of $\mathrm{ZIF}-8$ content.
$\mathrm{CO}_{2}$ permeability remarkably increases without sacrificing the gas selectivity, which is still beneficial for approaching the "Robeson upper-bound".

\subsection{Gas separation performance of the Pebax/ZIF-8/IL composite membranes}

3.4.1 Effect of IL addition on the gas diffusivity and solubility coefficients. Considering the relatively high $\mathrm{CO}_{2}$ permeability and $\mathrm{CO}_{2} / \mathrm{N}_{2}, \mathrm{CO}_{2} / \mathrm{CH}_{4}$ selectivity, the Pebax/ZIF-8(15\%)/ $[\mathrm{Bmim}]\left[\mathrm{NTf}_{2}\right]$ composite membranes with IL content varying from 0 to $80 \mathrm{wt} \%$ were prepared herein. The effect of IL addition on the diffusivity and solubility coefficients of $\mathrm{N}_{2}, \mathrm{CH}_{4}$, and $\mathrm{CO}_{2}$ for the Pebax/ZIF-8/IL membranes were investigated and are shown in Fig. 11.

The diffusivity coefficients of $\mathrm{N}_{2}, \mathrm{CH}_{4}$, and $\mathrm{CO}_{2}$ for the Pebax/ ZIF-8/IL membranes dramatically increased compared to that of Pebax/ZIF-8(15\%) membrane with the addition of IL, especially after $20 \mathrm{wt} \%$ IL content. IL acts as a low-molecular weight additive, leading to a more flexible structure and higher chain mobility, which can be concluded from DSC and SEM results. In addition, the decrease in the crystallinity of the Pebax/ZIF-8/IL membranes leads to a higher FFV. ${ }^{32}$ The high chain mobility and FFV facilitate gases diffusion leading to a higher gas diffusivity coefficient. ${ }^{32,34}$

$\mathrm{N}_{2}, \mathrm{CH}_{4}$, and $\mathrm{CO}_{2}$ diffusivity coefficients for the Pebax/ZIF-8/ IL membranes fluctuate with the IL content varying from 0-20
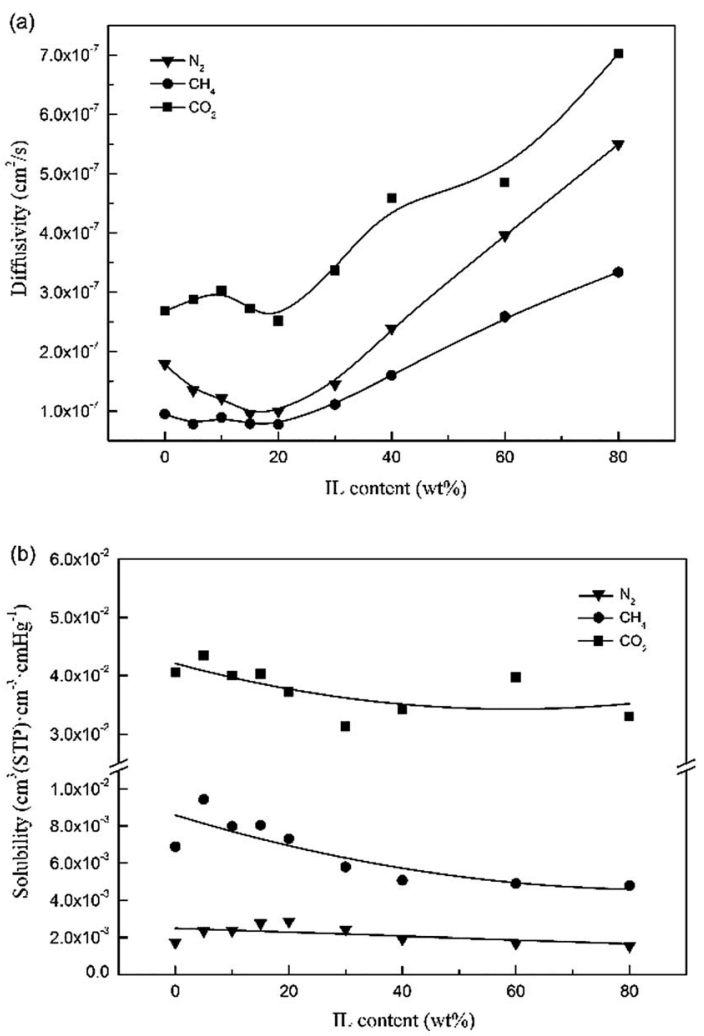

Fig. 11 (a) Diffusivity coefficients and (b) solubility coefficients of $\mathrm{N}_{2}$, $\mathrm{CH}_{4}$, and $\mathrm{CO}_{2}$ for the Pebax/ZIF-8(15\%) membrane and Pebax/ZIF-8/ IL membranes as a function of IL content. 


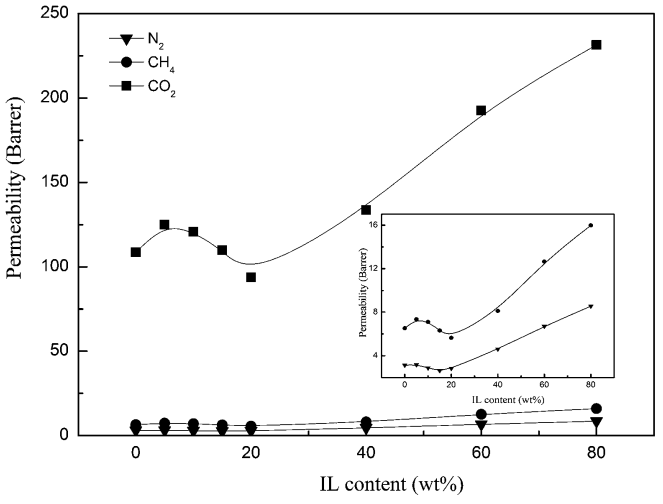

Fig. 12 Gas permeability of $\mathrm{N}_{2}, \mathrm{CH}_{4}$, and $\mathrm{CO}_{2}$ for the Pebax/ZIF$8(15 \%)$ membrane and Pebax/ZIF-8/IL membranes as a function of IL content.

wt $\%$ and there is a slight reduction in the $\mathrm{CH}_{4}$ diffusivity coefficients. SEM images show that the addition of IL fills the voids between the ZIF-8 particles and polymer, which will hinder the gas diffusion. Therefore, IL has two roles: the higher chain mobility and FFV of the prepared membranes facilitate gas diffusion, whereas a decrease in the number of voids between the ZIF-8 particles and polymer inhibits gas diffusion. Therefore, the reduction in the gas diffusivity coefficients appears to be more dependent on the blocking effect at a low IL content.

Fig. 11(b) shows that the $\mathrm{CH}_{4}$ and $\mathrm{CO}_{2}$ solubility coefficients of the Pebax/ZIF-8/IL membranes decrease with the IL addition compared to those of the Pebax/ZIF- $8(15 \%)$ membrane, and there was no remarkable change in the $\mathrm{N}_{2}$ solubility coefficients. These results are mainly caused by the solubility of the pure IL. The solubility coefficient of the Pebax/ZIF-8(15\%) membrane is $3.57 \times 10^{-2}\left(\mathrm{~cm}^{3}(\mathrm{STP})\right.$ per $\left.\left(\mathrm{cm}^{3} \mathrm{~cm} \mathrm{Hg}\right)\right)$, and the solubility coefficient of the pure IL is $3.115 \times 10^{-2}\left(\mathrm{~cm}^{3}(\mathrm{STP})\right.$ per $\left.\left(\mathrm{cm}^{3} \mathrm{~cm} \mathrm{Hg}\right)\right)$, as reported in the literature. ${ }^{40}$ The solubility of the pure IL is lower than that of the Pebax/ZIF-8(15\%) membrane, resulting in a slight decrease in the $\mathrm{CO}_{2}$ solubility coefficients for the Pebax/ZIF-8/IL with the increasing IL content. This observation is similar to those for $\mathrm{N}_{2}$ and $\mathrm{CH}_{4}$.

3.4.2 Effect of IL addition on the gas permeability and selectivity. Fig. 12 shows that $\mathrm{N}_{2}, \mathrm{CH}_{4}$, and $\mathrm{CO}_{2}$ permeabilities for Pebax/ZIF-8/IL membranes are significantly enhanced compared to those of the Pebax/ZIF-8(15\%) membrane with the addition of IL. For $\mathrm{CO}_{2}$, the permeability reached 231.4 barrer at an $80 \mathrm{wt} \%$ IL content, which is $111 \%$ higher than that of Pebax/ ZIF-8(15\%) membrane. The permeabilities of $\mathrm{N}_{2}$ and $\mathrm{CH}_{4}$ also increased by $174 \%$ and $145 \%$ compared to those of the Pebax/ ZIF-8(15\%) membrane. The enhancement in the permeability was attributed to the dramatic increase in the gas diffusivity coefficients. Therefore, IL increases the gas permeability of the Pebax/ZIF-8/IL membranes mainly by facilitating gas diffusion. Small fluctuations were permitted because of the fluctuations in the gas diffusivity coefficients with the IL content from $0-20 \mathrm{wt} \%$.

Fig. 13 shows that the $\mathrm{CO}_{2} / \mathrm{N}_{2}$ selectivity of the Pebax/ZIF-8/ IL membranes increases when the IL content is lower than 20

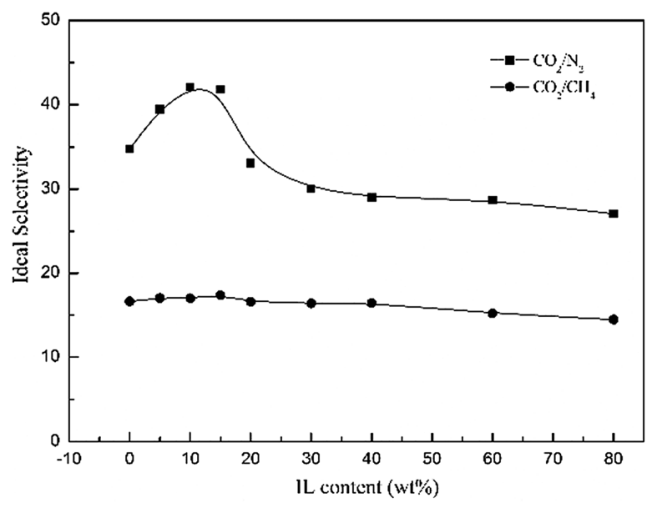

Fig. 13 Ideal selectivity of $\mathrm{CO}_{2} / \mathrm{N}_{2}$ and $\mathrm{CO}_{2} / \mathrm{CH}_{4}$ for the Pebax/ZIF$8(15 \%)$ membrane and Pebax/ZIF-8/IL membranes as a function of IL content.

wt\%, and the best $\mathrm{CO}_{2} / \mathrm{N}_{2}$ selectivity of the Pebax/ZIF-8/IL membranes is 42.07 at $10 \mathrm{wt} \%$ IL content. The addition of IL can improve the compatibility between the inorganic particles and polymer matrix. Therefore, the non-selective voids decrease and lead to a higher $\mathrm{CO}_{2} / \mathrm{N}_{2}$ selectivity of Pebax/ZIF-8/IL. However, the $\mathrm{CO}_{2} / \mathrm{N}_{2}$ selectivity of the Pebax/ZIF-8/IL membranes decreases at a high IL content (20-80 wt\%). This was attributed to the intrinsically lower $\mathrm{CO}_{2} / \mathrm{N}_{2}$ selectivity of the IL itself. Furthermore, there was almost no change in the $\mathrm{CO}_{2} /$ $\mathrm{CH}_{4}$ selectivity of the Pebax/ZIF-8/IL membranes.

To clearly display the gas separation performance of the prepared membranes, Robeson plots of the $\mathrm{CO}_{2} / \mathrm{N}_{2}$ performance are displayed in Fig. 14. The 2008 upper-bound of $\mathrm{CO}_{2} /$ $\mathrm{N}_{2}$ is cited from the literature. ${ }^{41}$ In addition, the threecomponent composite membranes reported in other studies $^{17,18,42,43}$ are also presented in Fig. 14. As a result, Pebax/ $\mathrm{ZIF} / \mathrm{IL}$ membranes in this study show comparable $\mathrm{CO}_{2} / \mathrm{N}_{2}$ separation performance and there is a significant increase in the $\mathrm{CO}_{2}$ permeability. The $\mathrm{CO}_{2}$ permeability of all the prepared membranes was in the following order: Pebax-ZIF(15\%)-IL(80\%) $>$ Pebax-IL(80\%) > Pebax-ZIF(15\%) > pure Pebax membrane. Moreover, Pebax-ZIF(15\%)-IL(10\%) shows the highest $\mathrm{CO}_{2} / \mathrm{N}_{2}$

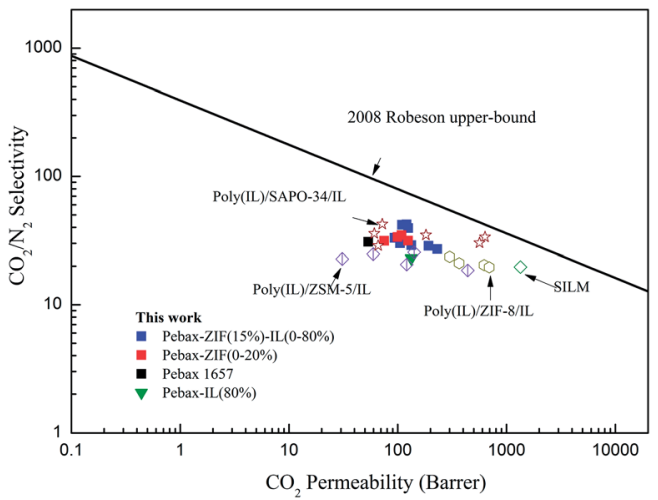

Fig. 14 Comparison of the membranes used in this study, SILMs, ${ }^{44}$ and the three-component MMMs reported in other studies ${ }^{17,18,42,43}$ for the $\mathrm{CO}_{2} / \mathrm{N}_{2}$ separation with the 2008 Robeson upper-bound. 
selectivity with a value of 42.07 , which is much higher than that of the $[\mathrm{Bmim}]\left[\mathrm{NTf}_{2}\right]$ supported membranes (19.68) reported in the literature. ${ }^{\mathbf{4 4}}$ Compared to the Pebax/ZIF-8 and Pebax/IL composite membranes, the Pebax/ZIF-8/IL membranes exhibited superior $\mathrm{CO}_{2}$ separation performance. In addition, the Pebax/ZIF-8/IL membranes can be an effective approach to avoid IL leakage, which is a conventional problem for the supported ionic liquid membranes (SILMs). Therefore, the incorporation of ZIF-8 and [Bmim] $\left[\mathrm{NTf}_{2}\right]$ into the polymer matrix is a promising way to efficiently separate $\mathrm{CO}_{2}$.

\section{Conclusions}

Herein, a series of composite membranes with high gas transport properties enhanced by IL were developed. The results showed that the addition of IL can enhance the gas permeability of the Pebax/IL membranes, and the anions of ILs play a significant role in determining the gas permeability, which is similar to the principle of gas solubility in pure IL. Moreover, both the affinity of IL for the polymer and the inherent gas selectivity capacity of the IL influence the gas separation performance of the Pebax/IL membranes. The reduction in the polymer crystallinity and the formation of narrow voids by ZIF-8 facilitate $\mathrm{CO}_{2}$ diffusion. In addition, a decrease in the diffusivity coefficients for $\mathrm{N}_{2}$ and $\mathrm{CH}_{4}$ can be observed. The addition of IL can improve the compatibility between the inorganic particles and the polymer matrix, thus the non-selective voids decrease and lead to a higher $\mathrm{CO}_{2} / \mathrm{N}_{2}$ selectivity of the Pebax/ZIF-8/IL. High gas transport properties were obtained in the membranes with the addition of IL. This was attributed to the flexible structure and high FFV of the membranes with a decrease in the crystallinity, which promotes gas diffusion. The $\mathrm{CO}_{2}$ permeability of the Pebax/ZIF-8(15\%)/IL(80\%) composite membrane was 4.3 times higher than that of the pure Pebax membrane without sacrificing the $\mathrm{CO}_{2} / \mathrm{N}_{2}$ selectivity. Therefore, the three-component composite membranes containing IL, inorganic fillers, and organic polymer membranes with high gas transport properties can be a promising approach for the efficient separation of $\mathrm{CO}_{2}$.

\section{Acknowledgements}

This work was financially supported by the National Natural Science Fund for Distinguished Young Scholars (No. 21425625), the National Natural Science Foundation of China (No. 21506219, No. 51574215, No. 21606233), and the Corporation Program with State Key Laboratory of Organic-Inorganic Composites, Beijing University of Chemical Technology (No. oic-201601005).

\section{Notes and references}

1 N. MacDowell, N. Florin, A. Buchard, J. Hallett, A. Galindo, G. Jackson, C. S. Adjiman, C. K. Williams, N. Shah and P. Fennell, Energy Environ. Sci., 2010, 3, 1645.
2 S. D. Kenarsari, D. Yang, G. Jiang, S. Zhang, J. Wang, A. G. Russell, Q. Wei and M. Fan, RSC Adv., 2013, 3, 2273922773.

3 D. L. Gin and R. D. Noble, Science, 2011, 332, 674-676.

4 R. Khalilpour, K. Mumford, H. Zhai, A. Abbas, G. Stevens and E. S. Rubin, J. Cleaner Prod., 2015, 103, 286-300.

5 A. Kılıç, Ç. Atalay-Oral, A. Sirkecioğlu, Ş. B. TantekinErsolmaz and M. G. Ahunbay, J. Membr. Sci., 2015, 489, 8189.

6 T. Rodenas, M. van Dalen, E. García-Pérez, P. Serra-Crespo, B. Zornoza, F. Kapteijn and J. Gascon, Adv. Funct. Mater., 2014, 24, 249-256.

7 T.-H. Bae and J. R. Long, Energy Environ. Sci., 2013, 6, 3565. 8 L. B. J. Deng, S. J. Zeng, X. P. Zhang, Y. Nie, L. Y. Deng and S. J. Zhang, RSC Adv., 2016, 6, 45184-45192.

9 H. Z. Chen, P. Li and T.-S. Chung, Int. J. Hydrogen Energy, 2012, 37, 11796-11804.

10 M. Yu, H. H. Funke, R. D. Noble and J. L. Falconer, J. Am. Chem. Soc., 2011, 133, 1748-1750.

11 P. K. Prajapati, A. M. Kansara and P. S. Singh, RSC Adv., 2016, 6, 88943-88953.

12 A. F. Bushell, P. M. Budd, M. P. Attfield, J. T. Jones, T. Hasell, A. I. Cooper, P. Bernardo, F. Bazzarelli, G. Clarizia and J. C. Jansen, Angew. Chem., Int. Ed., 2013, 52, 1253-1256.

13 M. Rezakazemi, A. Ebadi Amooghin, M. M. MontazerRahmati, A. F. Ismail and T. Matsuura, Prog. Polym. Sci., 2014, 39, 817-861.

14 T. Rodenas, I. Luz, G. Prieto, B. Seoane, H. Miro, A. Corma, F. Kapteijn, F. X. Llabres i Xamena and J. Gascon, Nat. Mater., 2015, 14, 48-55.

15 Z. Lei, C. Dai and B. Chen, Chem. Rev., 2014, 114, 1289-1326. 16 Z. Dai, R. D. Noble, D. L. Gin, X. Zhang and L. Deng, J. Membr. Sci., 2016, 497, 1-20.

17 Y. C. Hudiono, T. K. Carlisle, A. L. LaFrate, D. L. Gin and R. D. Noble, J. Membr. Sci., 2011, 370, 141-148.

18 Y. C. Hudiono, T. K. Carlisle, J. E. Bara, Y. Zhang, D. L. Gin and R. D. Noble, J. Membr. Sci., 2010, 350, 117-123.

19 D. F. Mohshim, H. Mukhtar and Z. Man, Sep. Purif. Technol., 2014, 135, 252-258.

20 T. Khosravi and M. Omidkhah, $R S C A d v ., 2015$, 5, 1284912859.

21 J. Lillepaerg, P. Georgopanos, T. Emmler and S. Shishatskiy, RSC Adv., 2016, 6, 11763-11772.

22 S. Shahid, K. Nijmeijer, S. Nehache, I. Vankelecom, A. Deratani and D. Quemener, J. Membr. Sci., 2015, 492, 21-31.

23 S. Zhao, X. Cao, Z. Ma, Z. Wang, Z. Qiao, J. Wang and S. Wang, Ind. Eng. Chem. Res., 2015, 54, 5139-5148.

24 T. K. Carlisle, J. E. Bara, C. J. Gabriel, R. D. Noble and D. L. Gin, Ind. Eng. Chem. Res., 2008, 47, 7005-7012.

25 S. Wang, Y. Liu, S. Huang, H. Wu, Y. Li, Z. Tian and Z. Jiang, J. Membr. Sci., 2014, 460, 62-70.

26 M. J. C. Ordoñez, K. J. Balkus, J. P. Ferraris and I. H. Musselman, J. Membr. Sci., 2010, 361, 28-37.

27 S. Kanehashi, M. Kishida, T. Kidesaki, R. Shindo, S. Sato, T. Miyakoshi and K. Nagai, J. Membr. Sci., 2013, 430, 211222. 
28 D. Zhao, J. Ren, H. Li, X. Li and M. Deng, J. Membr. Sci., 2014, 467, 41-47.

29 M. C. McCarthy, V. Varela-Guerrero, G. V. Barnett and H.-K. Jeong, Langmuir, 2010, 26, 14636-14641.

30 T. Zhou, L. Luo, S. Hu, S. Wang, R. Zhang, H. Wu, Z. Jiang, B. Wang and J. Yang, J. Membr. Sci., 2015, 489, 1-10.

31 H. Wu, X. Li, Y. Li, S. Wang, R. Guo, Z. Jiang, C. Wu, Q. Xin and X. Lu, J. Membr. Sci., 2014, 465, 78-90.

32 H. Rabiee, A. Ghadimi and T. Mohammadi, J. Membr. Sci., 2015, 476, 286-302.

33 S. Feng, J. Ren, Z. Li, H. Li, K. Hua, X. Li and M. Deng, Int. J. Greenhouse Gas Control, 2013, 19, 41-48.

34 A. Ghadimi, M. Amirilargani, T. Mohammadi, N. Kasiri and B. Sadatnia, J. Membr. Sci., 2014, 458, 14-26.

35 A. Car, C. Stropnik, W. Yave and K.-V. Peinemann, J. Membr. Sci., 2008, 307, 88-95.
36 R. Surya Murali, A. F. Ismail, M. A. Rahman and S. Sridhar, Sep. Purif. Technol., 2014, 129, 1-8.

37 M. C. McCarthy, V. Varela-Guerrero, G. V. Barnett and H.-K. Jeong, Langmuir, 2010, 26, 14636-14641.

38 H. Lin and B. D. Freeman, J. Mol. Struct., 2005, 739, 57-74.

39 H. Q. Lin and B. D. Freeman, Macromolecules, 2005, 38, 8394-8407.

40 J. E. Bara, T. K. Carlisle, C. J. Gabriel, D. Camper, A. Finotello, D. L. Gin and R. D. Noble, Ind. Eng. Chem. Res., 2009, 48, 2739-2751.

41 L. M. Robeson, J. Membr. Sci., 2008, 320, 390-400.

42 L. Hao, P. Li, T. Yang and T.-S. Chung, J. Membr. Sci., 2013, 436, 221-231.

43 R. Shindo, M. Kishida, H. Sawa, T. Kidesaki, S. Sato, S. Kanehashi and K. Nagai, J. Membr. Sci., 2014, 454, 330338.

44 P. Scovazzo, J. Membr. Sci., 2009, 343, 199-211. 